\title{
The effects of nucleotide usage in key nucleotide positions +4 and -3 flanking start codon on translation levels mediated by IRES of hepatitis $\mathrm{C}$ virus
}

\author{
P. MA ${ }^{1 *}$, X.-X. MA ${ }^{1 *}$, Q.-Y. CHANG ${ }^{1}$, L.-J. LI ${ }^{1}$, Y.-N. WANG ${ }^{2}$, Y.-P. FENG ${ }^{1}$, Z.-R. MA ${ }^{1 *}$, J-H. ZHOU ${ }^{*}$ \\ ${ }^{1}$ Center for Biomedical Research, Northwest Minzu University, Lanzhou, 730030, P. R. China; \\ ${ }^{2}$ State Key Laboratory of Veterinary Etiological Biology, Lanzhou Veterinary Research Institute, Chinese Academy of Agricultural \\ Sciences, Lanzhou, 730046, Gansu, P. R. China
}

Received December 12, 2017; accepted March 20, 2018; accepted October 15, 2018

\begin{abstract}
Summary. - Internal ribosomal entry site (IRES) functions as a cis-acting RNA element, which drives an alternative and cap-independent translation initiation pathway. Currently, there are few studies on effects of nucleotide usages at key nucleotide positions +4 and -3 flanking start codon mediated by IRES of hepatitis $\mathrm{C}$ virus (HCV). Herein, we focus on the effect of nucleotide usages at -3 and +4 positions mediated by HCV IRES. The nucleotide contexts flanking AUG start codon employed by HCV IRES is firstly analyzed. We found that each position in the six nucleotide positions $(-4$ to +6$)$ flanking start codon of HCV has a strong tendency to select the specific nucleotide. A set of bicistronic expression vectors containing CAT gene, HCV IRES and EGFP gene were constructed, including 16 different nucleotide combinations at position -3 and +4 . Each set, in which nucleotide at the -3 and +4 position has been changed into different nucleotides, included 16 types of bicistronic expression vectors. It was found that the purine nucleotide at the position -3 or +4 obviously impacts on HCV IRES-related expression, and IRES-driven translation is potentially influenced by the Kozak rule. Our results suggest that optimization of nucleotides at positions -3 and +4 is a convenient and efficient way to enhance the level of IRES-mediated translation.
\end{abstract}

Keywords: Cap-independent translation; internal ribosomal entry site; hepatitis C virus; bicistronic expression vector; translation efficiency

\section{Introduction}

The hepatitis $\mathrm{C}$ virus (HCV) is one of the most common blood-borne pathogens and results in acute and chronic liver diseases (Szabo et al., 2015). Due to an error-prone replication mechanism mediated by the viral-encoded RNA polymerase and the ability to survive mutation, $\mathrm{HCV}$ evolves rapidly and has extensive sequence diversity (Choo et al., 1991; Yuan et al., 2017). In 5' untranslated region (5' UTR), the internal ribosomal entry site (IRES) of HCV is

*Corresponding author. E-mail: zhoujianhua03@caas.cn; phone: +86-931-2938311. " The two authors contributed equally to this work.

Abbreviations: $\mathrm{CAT}=$ chloramphenicol acetyl transferase; EGFP = enhanced green fluorescent protein; $\mathrm{HCV}=$ hepatitis $\mathrm{C}$ virus; IRES = internal ribosomal entry site the most highly conserved region among various genotypes, its IRES plays an important role in the viral cycle and provides a potent target for antiviral agents (Fraser and Doudna, 2007). As for translation initiation mechanisms, there are two major mechanisms in eukaryotic translation systems, namely 5 ' cap-dependent translation initiation mechanism and $5^{\prime}$ cap-independent mechanism mediated by internal ribosome entry site (IRES) element (Mailliot and Martin, 2017). It has been accepted that initiation of translation of HCV RNA starts by a cap-independent mechanism mediated by IRES. Compared with the mechanism of translation initiation mediated by $5^{\prime}$ cap structure [methyl-7-G(5')pppG(5')N] (Green and Noller, 1997), the highly ordered structures within IRES elements are absolutely required for IRES activity (Balvay et al., 2009). By the use of a toe-print assay to determine the position of the ribosome on the mRNA, the HCV IRES was found to recruit the small ribosomal 
subunit directly to the ribosome, scanning to the initiation codon would not be required to initiate protein synthesis. Furthermore, the introduction of an initiation codon that is 7 nucleotides upstream, or 8 nucleotides downstream, of the correct initiation codon is not recognized by the ribosome, indicating that the structure of the HCV IRES is highly specialized in placing the correct initiation codon close to the $40 \mathrm{~S}$ ribosomal peptidyl (P) site. As for the secondary structure of domain IV of HCV IRES (Fraser and Doudna, 2007), this domain includes a loop, which is composed of 7 nucleotides, namely the (-3)AUC AUG (+4)A motif in positions -3 to +4 . As for translation initiation mediated by cap-dependent mechanism, nucleotide context surrounding start codon influences the situation of ribosome scanning (Kozak, 1986; Kozak, 1987). Mutations occurring at position -3 and +4 of this nucleotide context can weaken the abilities of ribosomes to recognize the corresponding start codon (Kozak, 1997; Kozak, 2003). The mechanism of ribosomal recruitment onto the IRES element of $\mathrm{HCV}$ is significantly different from that mediated by 5 ' cap-structure. Without the participation of eIF4F, eIF4A and eIF4B, the $48 \mathrm{~S}$ initiation complex can be assembled onto the HCV IRES element (Kieft et al., 2001; Otto et al., 2002; Laletina et al., 2006). During the course of the positioning of the IRES element of HCV onto the surface of the $40 \mathrm{~S}$ ribosomal subunit, the specific nucleotide sequence structure of the IRES element can induce a conformational change of $40 \mathrm{~S}$ ribosome, resulting in positioning the start codon into the $\mathrm{P}$ site of the ribosome without ribosomal scanning (Pestova et al., 1998; Spahn et al., 2001). Here, we are interested in whether or not the specific nucleotide usage in positions -3 and +4 flanking the start codon would take part in mediating the translation initiation efficiencies under the HCV IRES element. Currently, there have been many studies on the role of functional and structural diversity of the HCV IRES element in mediating the translation initiation, however, there are a few reports about the specific nucleotide positions flanking the start codon under the control of HCV IRES element. In this study, we focused on the nucleotide usage at positions -3 and +4 surrounding the start codon for influencing the downstream gene expression level in order to provide insights into the translation initiation mediated by the HCV IRES element.

\section{Materials and Methods}

HCV genomes data. To reflect the genetic diversity for HCV genome, the 273 genomes of HCV, which were collected from different countries at different times, were downloaded from the National Center for Biotechnology Information (NCBI) (http:// www.ncbi.nlm.nih.gov/Genbank/) (listed in Table S1).

Analysis of nucleotide usage at translation initiation region of HCV genome. To analyze the features of nucleotide usage at posi- tions-3 \& +4 for HCV genome, we employed a simple method to estimate the magnitudes of nucleotide usage at the translation initiation region (positions $-3,-2,-1$ and $+4,+5$ and +6 ), namely $R=n_{i} /$ $N_{\text {opt }}$. In detail, $\mathrm{R}_{\mathrm{i}}$ represents the usage magnitude of the nucleotide $i$ at the target position of the $273 \mathrm{HCV}$ sequences, $n_{i}$ is the frequency of the interesting nucleotide $i$ at the target position, $\mathrm{N}_{\mathrm{opt}}$ is the frequency of the optimal nucleotide at this position. The formula for $\mathrm{R}_{\mathrm{i}}$ was calculated for estimating the usage magnitudes of the four types of nucleotides at each position of translation initiation region.

Plasmids construction. To estimate the effects of each type of nucleotides at the positions $-3 \&+4$ on the translation initiation efficiencies mediated by the HCV IRES element, we downloaded the HCV IRES sequence (GenBank Acc. No. AB016785) from GenBank of NCBI website and this IRES sequence was artificially synthesized by the GENEWIZ (China) Co., Ltd. Bicistronic reporter constructs were engineered to contain the IRES element. The upstream chloramphenicol acetyl transferase (CAT) and downstream enhanced green fluorescent protein (EGFP) genes monitor cap-dependent and IRES-dependent translation, respectively. It was noted that the target IRES sequence was fused in frame of CAT coding sequence. During constructing the bicistronic reporter constructs containing the specific IRES, all performances were carried out via standard techniques, following Molecular Cloning (A Laboratory Manual, $3^{\text {rd }}$ ed. Cold Spring Harbor). First step was that acquisitions of CAT coding sequence, IRES sequence and EGFP coding sequence were achieved by PCR method with the specific forward \& reverse PCR primers (Table S2). In detail, CAT gene was amplified from the plasmid pcDNA3.1(+)/CAT (Invitrogen), EGFP gene was amplified from the plasmid pEGFP-N1 (CLONTECH Laboratories, Inc.), and the HCV IRES element was obtained from plasmid pUC57-IRES(III) (Invitrogen). Second step is that the CAT gene and the IRES sequence were amplified via fusion PCR with a set of primers to obtain the cloned fragments CAT-IRES (Table S3). The fusion PCR amplifications involved 35 cycles of $94^{\circ} \mathrm{C}$ for $10 \mathrm{~s}$, $58^{\circ} \mathrm{C}$ for $15 \mathrm{~s}$, and $68^{\circ} \mathrm{C}$ for $70 \mathrm{~s}$, followed by a final elongation step at $72^{\circ} \mathrm{C}$ for $10 \mathrm{~min}$. Third step is that the fragment of CAT-IRES and EGFP coding sequence were carried out via fusion PCR with a set of primers to obtain the cloned fragments CAT-IRES-EGFP. The program of fusion PCR amplifications was the same as that of the fusion PCR for the cloned fragment of CAT-IRES (Table S4). The resulting cloned fragments were processed by digestion with $\mathrm{B} a m \mathrm{HI}$ and $\mathrm{Xba \textrm {I }}$ and ligated into similarly digested pcDNA3.1 $(+)$. There were 16 bicistronic reporter constructs, which contain the specific translation initiation regions. By sequencing assay of the two resulting plasmids, the 16 resulting bicistronic reporter constructs were shown to contain the correct fragments (Table 1).

Transient expression assay. Because the 16 bicistronic reporter plasmids contained different nucleotide usage at the position +4 in the translation initiation region, the different nucleotide usage can result in different codon usages, which were located downstream of the start codon. The factor of tRNA abundance pairing to the specific codon needed to be analyzed whether or not it would work in influencing EGFP gene expression. As for the cell culture using 
Table 1. The information about the nucleotide context of translation initiation regions in the $\mathbf{1 6}$ bicistronic reporter constructs

\begin{tabular}{|c|c|c|}
\hline No. & $\begin{array}{c}\text { Name of the bicistronic } \\
\text { reporter construct }\end{array}$ & The nucleotide context \\
\hline 1 & pCAT-IRES - -EGFP & $(-3)$ TCC ATG $(+4)$ GTG \\
\hline 2 & pCAT-IRES 2 -EGFP & $(-3)$ TCC ATG $(+4)$ CTG \\
\hline 3 & pCAT-IRES -EGFP & $(-3)$ TCC ATG $(+4)$ TTG \\
\hline 4 & pCAT-IRES $_{4}-$ EGFP & $(-3)$ TCC ATG $(+4)$ ATG \\
\hline 5 & pCAT-IRES - EGFP & $(-3)$ CCC ATG $(+4)$ GTG \\
\hline 6 & pCAT-IRES 6 -EGFP & $(-3)$ CCC ATG $(+4)$ CTG \\
\hline 7 & pCAT-IRES - -EGFP & $(-3) \mathrm{CCC} \mathrm{ATG}(+4) \mathrm{TTG}$ \\
\hline 8 & pCAT-IRES -EGFP & $(-3)$ CCC ATG (+4)ATG \\
\hline 9 & pCAT-IRES $_{9}$-EGFP & $(-3) \mathrm{ACC} \mathrm{ATG}(+4) \mathrm{GTG}$ \\
\hline 10 & pCAT-IRES $_{10}$-EGFP & $(-3)$ ACC ATG (+4)CTG \\
\hline 11 & pCAT-IRES $_{11}$-EGFP & (-3)ACC ATG (+4)TTG \\
\hline 12 & pCAT-IRES $_{12}$-EGFP & $(-3) \mathbf{A C C ~ A T G ~ ( + 4 ) \mathbf { A T G }}$ \\
\hline 13 & pCAT-IRES $_{13}$-EGFP & $(-3)$ GCC ATG $(+4)$ GTG \\
\hline 14 & pCAT-IRES $_{14}$-EGFP & $(-3)$ GCC ATG $(+4)$ CTG \\
\hline 15 & pCAT-IRES $_{15}$-EGFP & $(-3)$ GCC ATG (+4)TTG \\
\hline 16 & pCAT-IRES $_{16}$-EGFP & $(-3)$ GCC ATG (+4)ATG \\
\hline
\end{tabular}

as the target cell of transient transfection, we used cell line CHOK1 (Chinese hamster ovary), because the tRNA copy numbers of $\mathrm{CHO}-\mathrm{K} 1$ had been reported in the Genomic tRNA Database (http:// gtrnadb.ucsc.edu/\#eukarya). CHO-K1 cells in 6-well plate were transfected one day after plating, when the monolayers reached to about $80 \%$ confluence. Following the protocol provided with Lipofectamine $^{\mathrm{rm}} 2000$ Reagent (Invitrogen), each plate was transfected with $500 \mu \mathrm{l}$ of Opti-MEM ${ }^{\mathrm{m}}$ Medium mixture including $4 \mu \mathrm{l}$ of Lipofectamine $^{\mathrm{rm}} 2000$ and $4 \mu \mathrm{g}$ of purified plasmid DNA. Twenty-four hours after transfection, the cells were collected. Soluble extracts of CHO-K1 cells were prepared by lysing the cells in $120 \mathrm{mmol} / \mathrm{l}$ $\mathrm{NaCl}, 50 \mathrm{mmol} / \mathrm{l}$ Tris- $\mathrm{HCl}$ ( $\mathrm{pH} \mathrm{7.8)}$, and $0.5 \%$ of Nonidet P-40, followed by centrifugation at $12,000 \mathrm{rpm}$ for $5 \mathrm{~min}$ in a $1.5-\mathrm{ml}$ centrifuge tube. These products were analyzed by sodium dodecyl sulfate-polyacrylamide gel electrophoresis (SDS-PAGE; 10\% gels) and detected by immunoblotting with a rabbit anti-CAT antibody (Sigma) and murine anti-EGFP antibody (Sigma) with horseradish peroxidase (HRP)-labeled anti-species secondary antibodies (Sigma) and enhanced chemiluminescence (ECL; Thermo).
Data analysis. To analyze the translation magnitudes mediated by different nucleotides at the positions -3 and +4 , the products translated by CAT gene and EGFP gene were tested and confirmed. The translation ratio $(R)$ was calculated by the formula $R=$ EGFP/ CAT. The results were analyzed by the ANOVA test performed by SPSS 11.5 software and were considered significantly different when $\mathrm{P}<0.05$.

\section{Results}

Nucleotide usage at the positions -3 and +4 surrounding start codon

By analyzing the two target positions surrounding the start codon, we found the bias of nucleotide usage existed in translation initiation region of $\mathrm{HCV}$ genome. As for the target positions of this study, adenine had strong tendencies to exist at the position -3 and +4 (Table 2 ). This result showed that nucleotide usage at the two positions is under strong natural selection rather than mutation pressure, even though $\mathrm{HCV}$ as an RNA virus has high mutation rates.

The effect of the key nucleotide context flanking the start codons on gene transcription

To explore the effect of -3 and +4 mutations on IRES mediated translation, we developed bicistronic expression vector, in which single transcripts contained the CAT and EGFP genes under the control of human cytomegalovirus (CMV) promoter. As shown in Fig. 1, the IRES was inserted into the junction of these two genes, and single or double mutations of positions -3 and +4 flanking the start codon used by IRES for the translation initiation of EGFP were introduced into IRES-based constructs, resulting in 16 constructs with different combinations for each IRES. As for these two reporter genes, CAT and EGFP, both were detected in IRES-based constructs, from which CAT was translated by a cap-independent manner and EGFP translation as mediated by HCV IRES element. Real-time RT-PCR was performed at 24 hours post-transfection in raw cell extracts

Table 2. Frequencies and relative adaptiveness $\left(R_{i}\right)$ of the nucleotide surrounding the start codon

\begin{tabular}{|c|c|c|c|c|c|c|c|c|}
\hline Position & $F_{\mathrm{A}}$ & $F_{\mathrm{U}}$ & $F_{\mathrm{C}}$ & $F_{\mathrm{G}}$ & $R_{\mathrm{A}}$ & $\boldsymbol{R}_{\mathrm{U}}$ & $\boldsymbol{R}_{\mathrm{C}}$ & $\boldsymbol{R}_{\mathrm{G}}$ \\
\hline-3 & 235 & 1 & 1 & 0 & 1.00 & 0.004255 & 0.004255 & 0 \\
\hline-2 & 13 & 55 & 169 & 0 & 0.076923 & 0.325444 & 1.00 & 0 \\
\hline-1 & 1 & 1 & 23 & 0 & 0.043478 & 0.043478 & 1.00 & 0 \\
\hline AUG & ------ & ------ & ------ & ------ & ------- & ------- & ---- & ------ \\
\hline+4 & 235 & 0 & 0 & 2 & 1.00 & 0.00 & 0.00 & 0.008511 \\
\hline+5 & 1 & 0 & 1 & 235 & 0.004255 & 0.00 & 0.004255 & 1.00 \\
\hline+6 & 1 & 0 & 236 & 0 & 0.004237 & 0.00 & 1.00 & 0.00 \\
\hline
\end{tabular}




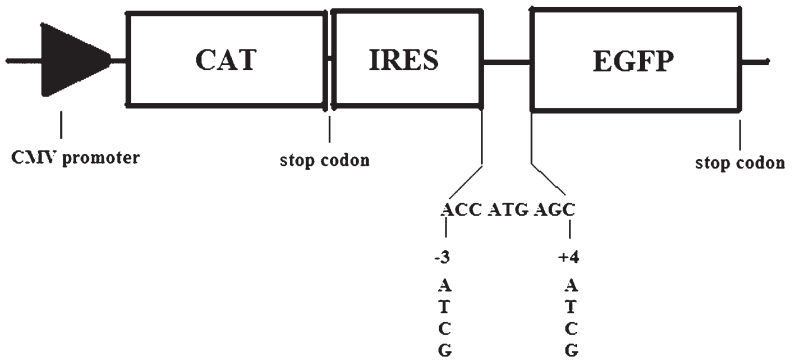

pCAT-IRES-EGFP

Fig. 1

The organization of bicistronic expression vector (pCAT-IRES-EGFP)

(a)

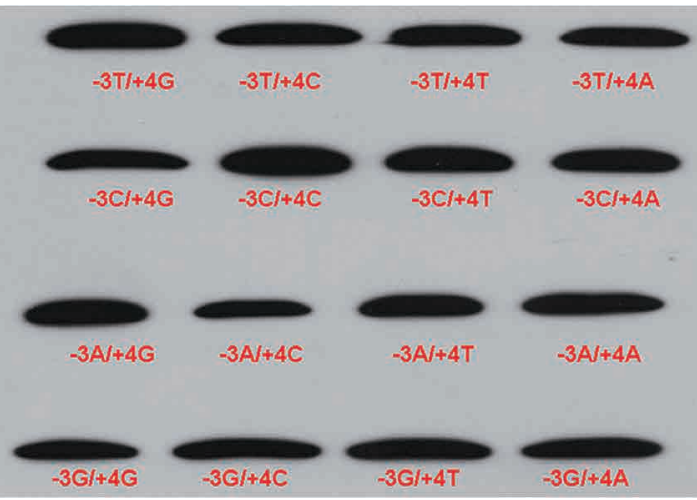

(b)

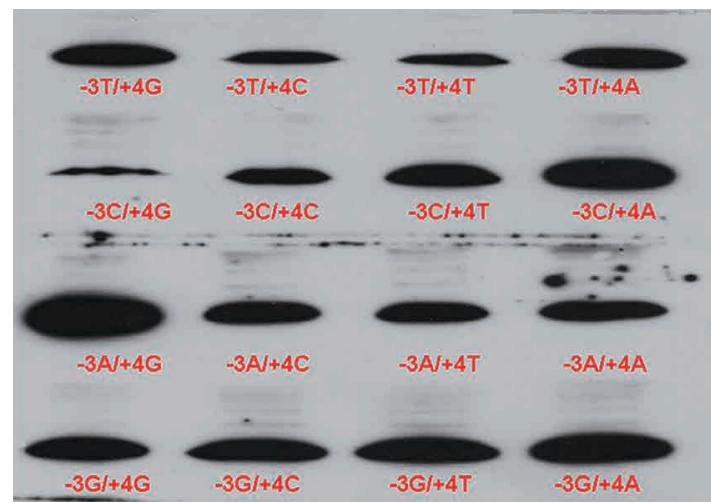

Fig. 2

Western blot assay for the detection of the protein product of CAT gene and EGFP gene translated by 16 different sets of pCAT-IRES-EGFP

(a) CAT protein products, (b) EGFP protein products.

transfected with different bicistronic reporter constructs. The results showed similar levels of reporter RNAs in each reaction (Fig. S1), suggesting that the changes of nucleotides at the positions -3 and +4 did not affect the transcription levels of reporter genes.

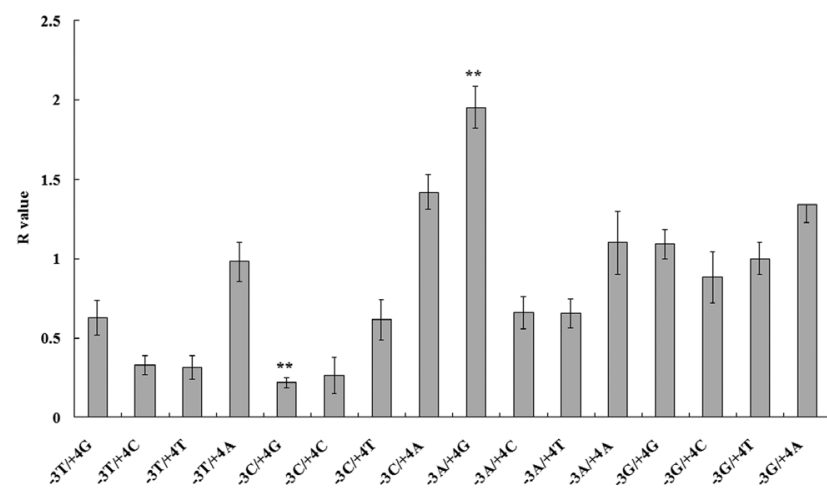

Fig. 3

Quantification of CAT and EGFP protein expression translated by 16 different sets of pCAT-IRES-EGFP vectors caused by the changes of nucleotide usages at positions -3 and +4 surrounding the start codon

The effect of the key nucleotide context flanking the start codons on gene expression

Twenty-four hours after transient transfection, the 16 raw cell extracts transfected by the specific bicistronic reporter construct were collected. Through western blotting assay we showed that the two reporter genes can be translated in CHO cells (Fig. 2). Furthermore, while CAT gene expression levels were similar, the expression levels of EGFP gene mediated by different nucleotides at the positions -3 and +4 were different. As for the translation ratios affected by different nucleotides at the positions of interest, the relative expression ratio of EGFP to CAT was calculated to represent the relative translation efficiency of IRES with specific nucleotide context around AUG start codon. In comparison, the relative translation efficiency ( $\mathrm{R}$ value) driven by HCV IRES (-3A, $+4 \mathrm{G})$ was highest $(\mathrm{p}<0.05)$, however, the relative translation efficiency (R value) mediated by HCV IRES $(-3 \mathrm{C},+4 \mathrm{G})$ was lowest $(\mathrm{P}<0.05)$ (Fig. 3). In addition, as shown in Fig. 3, when the position +4 was nucleotide $\mathrm{A}$, the expression of EGFP mediated by HCV IRES could be improved regardless of the nucleotide types in the position -3; and when the position -3 was nucleotide $G$, the expression of EGFP also could be enhanced, regardless of the nucleotide type in the position +4 . These results strongly implied that the nucleotide related to purine at the position -3 or +4 impacted the expression of gene mediated by HCV IRES.

\section{Discussion}

From the previous detailed mutational analyses, the Kozak sequence $(-3 \mathrm{~A} / \mathrm{GCC} \underline{\mathrm{ATG}}+4)$ has been defined as the most favorable context for translation initiation in eukaryotes mediated by 5 'cap-dependent mechanism under normal 
conditions (Hendrickx et al., 2014; Mohan et al., 2014; Ferretti et al., 2017). Of all the nucleotides around the AUG start codon, the nucleotides at positions -3 and +4 have dominant effects on translation efficiency (Kozak, 2003). Herein, this study shows that the positions -3 and +4 surrounding the start codon play important roles in gene expression mediated by HCV IRES. Compared with the gene expression mediated by HCV IRES $(-3 \mathrm{~A},+4 \mathrm{~A})$, the EGFP gene expression mediated by IRES $(-3 \mathrm{~A},+4 \mathrm{G})$, which is similar with that of the key positions of Kozak sequence, is higher. To some degree, the tRNA abundances are always impacting the translation efficiency of the specific gene, because translation speed and ribosomal density are encoded by coding sequences and the tRNA abundance pool (Tuller et al., 2010; Sun et al., 2018). According to tRNA copy numbers for the tRNA abundance pool in CHO cell line (Genomic tRNA Database), when the position +4 mutates different nucleotide types in bicistronic reporter plasmids, the tRNA abundances for the second codon (+4XTG+6, X means any nucleotide, tRNA copy number for GTG is 9, tRNA copy number for CTG is 10, tRNA copy number for TTG is 4, tRNA copy number for ATG is 16) following the start codon have no obvious effect on mediating the EGFP gene expression levels. This result implies that nucleotide context at +4 nucleotide position might influence the local structural formation rather than tRNA abundances, leading to the changes of gene expression mediated by HCV IRES (Jaafar et al., 2016; Bugaud et al., 2017; Ma et al., 2018; Mengardi et al., 2017; Ross et al., 2017; Zhu et al., 2017). Of note, the results show that the positions $-3 \mathrm{~A}$ and $+4 \mathrm{G}$ had a better performance in improving the translation efficiency mediated by HCV IRES than the preferred nucleotide usage bias $(-3 \mathrm{~A},+4 \mathrm{~A})$ in the positions $-3 \&+4$ of the translation initiation region of $\mathrm{HCV}$, implying that the Kozak-like nucleotide context $(-3 \mathrm{~A},+4 \mathrm{G})$ probably impacts the ribosome binding to the translation initiation region of $\mathrm{HCV}$. The HCV IRES has a capability to direct the initiator tRNA to the ribosomal $\mathrm{P}$ site during internal initiation and this IRES, which depends on modular architecture, plays important role in the gene expression by cap-independent mechanisms (Yamamoto et al., 2015).

The usage of IRES in bicistronic expression plasmids enables the expression of two genes controlled by one promoter in the same cells, which are important tools in today's cell biology (Fajardo et al., 2012; Ma et al., 2016). In order to obtain ratio-controlled or improved IRES-mediated protein expression, many methods were developed, for example, removal of unnecessary AUG start codon, using multiple IRES elements (Bouabe et al., 2008; Koh et al., 2013). On the basis of our data, it is clear that nucleotide mutations at position -3 and +4 flanking start codon could be an efficient and simple way to achieve maximal protein translation when viral IRES are used for heterologous co-expression. Since the IRES element exhibits cell- and tissue-specificity, our study broadens the choices of IRES and it can be recommended to select the IRES to be used for co-expression according to the cell type or tissue, rather than using encephalomyocarditis virus (EMCV) IRES, which is commonly proposed in all commercial IRES-based vectors.

Acknowledgments. This study was supported by the National Natural Science foundation of China (No. 31302100).

Supplementary information is available in the online version of the paper.

\section{References}

Balvay L, Soto Rifo R, Ricci EP, Decimo D, Ohlmann T (2009): Structural and functional diversity of viral IRESes. Biochim. Biophys. Acta 1789, 542-557. https://doi. org/10.1016/j.bbagrm.2009.07.005

Bouabe H, Fassler R, Heesemann J (2008): Improvement of reporter activity by IRES-mediated polycistronic reporter system. Nucleic. Acids. Res. 36, e28. https://doi.org/10.1093/nar/ gkm1119

Bugaud O, Barbier N, Chommy H, Fiszma N, Le Gall A, Dulin D, Saguy M, Westbrook N, Perronet K, Namy O (2017): Kinetics of CrPV and HCV IRES-mediated eukaryotic translation using single-molecule fluorescence microscopy. RNA 23, 1626-1635. https://doi.org/10.1261/ rna.061523.117

Choo QL, Richman KH, Han JH, Berger K, Lee C, Dong C, Gallegos C, Coit D, Medina-Selby R, Barr PJ, et al (1991): Genetic organization and diversity of the hepatitis C virus. Proc. Natl. Acad. Sci. USA 88, 2451-2455. https:// doi.org/10.1073/pnas.88.6.2451

Fajardo T, Jr, Rosas MF, Sobrino F, Martinez-Salas E (2012): Exploring IRES region accessibility by interference of footand-mouth disease virus infectivity. Plos One 7, e41382. https://doi.org/10.1371/journal.pone.0041382

Ferretti MB, Ghalei H, Ward EA, Potts EL, Karbstein K (2017): Rps26 directs mRNA-specific translation by recognition of Kozak sequence elements. Nat. Struct. Mol. Biol. 24, 700-707. https://doi.org/10.1038/nsmb.3442

Fraser CS, Doudna JA (2007): Structural and mechanistic insights into hepatitis $\mathrm{C}$ viral translation initiation. Nat. Rev. Microbiol. 5, 29-38. https://doi.org/10.1038/nrmicro1558

Green R, Noller HF (1997): Ribosomes and translation. Annu. Rev. Biochem. 66, 679-716. https://doi.org/10.1146/annurev. biochem.66.1.679

Hendrickx G, Boudin E, Fijalkowski I, Nielsen TL, Andersen M, Brixen K, Van Hul W (2014): Variation in the Kozak sequence of WNT16 results in an increased translation and is associated with osteoporosis related parameters. Bone 59, 57-65. https://doi.org/10.1016/j.bone.2013.10.022

Jaafar ZA, Oguro A, Nakamura Y, Kieft JS (2016): Translation initiation by the hepatitis $\mathrm{C}$ virus IRES requires eIF1A and ribosomal complex remodeling. eLife 5. https://doi. org/10.7554/eLife.21198 
Kieft JS, Zhou K, Jubin R, Doudna JA (2001): Mechanism of ribosome recruitment by hepatitis C IRES RNA. RNA 7, 194-206. https://doi.org/10.1017/S1355838201001790

Koh EY, Ho SC, Mariati Song Z, Bi X, Bardor M, Yang Y (2013): An internal ribosome entry site (IRES) mutant library for tuning expression level of multiple genes in mammalian cells. Plos One 8, e82100. https://doi.org/10.1371/journal. pone. 0082100

Kozak M (1986): Point mutations define a sequence flanking the AUG initiator codon that modulates translation by eukaryotic ribosomes. Cell 44, 283-292. https://doi. org/10.1016/0092-8674(86)90762-2

Kozak M (1987): An analysis of 5'-noncoding sequences from 699 vertebrate messenger RNAs. Nucleic. Acids. Res. 15, 8125-8148. https://doi.org/10.1093/nar/15.20.8125

Kozak M (1997): Recognition of AUG and alternative initiator codons is augmented by $\mathrm{G}$ in position +4 but is not generally affected by the nucleotides in positions +5 and +6. EMBO J. 16, 2482-2492. https://doi.org/10.1093/ emboj/16.9.2482

Kozak M (2003): Alternative ways to think about mRNA sequences and proteins that appear to promote internal initiation of translation. Gene 318, 1-23. https://doi.org/10.1016/ S0378-1119(03)00774-1

Laletina E, Graifer D, Malygin A, Ivanov A, Shatsky I, Karpova G (2006): Proteins surrounding hairpin IIIe of the hepatitis $\mathrm{C}$ virus internal ribosome entry site on the human $40 \mathrm{~S}$ ribosomal subunit. Nucleic. Acids. Res. 34, 2027-2036. https://doi.org/10.1093/nar/gkl155

Ma XX, Feng YP, Gu YX, Zhou JH, Ma ZR (2016): Effect of the nucleotides surrounding the start codon on the translation of foot-and-mouth disease virus RNA. Acta Virol. 60, 151-155. https://doi.org/10.4149/av 2016 $02 \quad 151$

Ma XX, Ma Z, Pan Q (2018): The challenges of long-term transcriptional gene silencing by RNA virus. Trends Biochem. Sci. 43, 649-650. https://doi.org/10.1016/j.tibs.2018.06.010

Mailliot J, Martin F (2017): Viral internal ribosomal entry sites: four classes for one goal. Wiley Interdiscip. Rev. RNA. doi: 10.1002/wrna.1458

Mengardi C, Limousin T, Ricci EP, Soto-Rifo R, Decimo D, Ohlmann T (2017): microRNAs stimulate translation initiation mediated by HCV-like IRESes. Nucleic. Acids. Res. 45, 4810-4824. https://doi.org/10.1093/nar/gkw1345

Mohan RA, van Engelen K, Stefanovic S, Barnett P, Ilgun A, Baars MJ, Bouma BJ, Mulder BJ, Christoffels VM, Postma AV (2014): A mutation in the Kozak sequence of GATA4 hampers translation in a family with atrial septal defects. Am. J. Med. Genet. A. 164A, 2732-2738. https://doi. org/10.1002/ajmg.a.36703

Otto GA, Lukavsky P J, Lancaster AM, Sarnow P, Puglisi JD (2002): Ribosomal proteins mediate the hepatitis $\mathrm{C}$ virus IRES-
HeLa 40S interaction. RNA 8, 913-923. https://doi. org $/ 10.1017 / \mathrm{S} 1355838202022057$

Pestova TV, Shatsky IN, Fletcher SP, Jackson RJ, Hellen CU (1998): A prokaryotic-like mode of cytoplasmic eukaryotic ribosome binding to the initiation codon during internal translation initiation of hepatitis $\mathrm{C}$ and classical swine fever virus RNAs. Genes Dev. 12, 67-83. https://doi. org/10.1101/gad.12.1.67

Ross MJ, Fidai I, Cowan JA (2017): Analysis of Structure-Activity Relationships Based on the Hepatitis C Virus SLIIb Internal Ribosomal Entry Sequence RNA-Targeting GGHYRFKCu Complex. Chembiochem. 18, 1743-1754. https:// doi.org/10.1002/cbic.201700228

Spahn CM, Kieft JS, Grassucci RA, Penczek PA, Zhou K, Doudna JA, Frank J (2001): Hepatitis C virus IRES RNA-induced changes in the conformation of the 40 s ribosomal subunit. Science 291, 1959-1962. https://doi.org/10.1126/science.1058409

Sun C, Yang F, Zhang Y, Chu J, Wang Y, Zhang Y, Li J, Li Y, Fan R, Li W, Huang X, Wu H, Fu Z, Jiang Z, Yin Y (2018): tRNA-derived fragments as novel predictive biomarkers for trastuzumab-resistant breast cancer. Cell. Physiol. Biochem. 49, 419-431. https://doi.org/10.1159/000492977

Szabo SM, Samp JC, Walker DR, Lane S, Cline SK, Gooch KL, Jimenez-Mendez R, Levy AR (2015): Liver-specific case fatality due to chronic hepatitis $C$ virus infection: a systematic review. Ann. Hepatol. 14, 618-630.

Tuller T, Carmi A, Vestsigian K, Navon S, Dorfan Y, Zaborske J, Pan T, Dahan O, Furman I, Pilpel Y (2010): An evolutionarily conserved mechanism for controlling the efficiency of protein translation. Cell 141, 344-354. https://doi. org/10.1016/j.cell.2010.03.031

Yamamoto H, Collier M, Loerke J, Ismer J, Schmidt A, Hilal T, Sprink T, Yamamoto K, Mielke T, Burger J, Shaikh TR, Dabrowski M, Hildebrand PW, Scheerer P, Spahn CM (2015): Molecular architecture of the ribosome-bound Hepatitis C Virus internal ribosomal entry site RNA. EMBO J. 34 3042-3058. https://doi.org/10.15252/embj.201592469

Yuan G, Liu J, Hu C, Huang H, Qi M, Wu T, Liang W, Li YP, Zhang YY, Zhou Y (2017): Genotype distribution and Molecular Epidemiology of hepatitis $\mathrm{C}$ virus in Guangzhou, China.: Predominance of genotype $\mathrm{lb}$ and increasing incidence of genotype 6a. Cell. Physiol. Biochem. 43, 775-787. https:// doi.org/10.1159/000481561

Zhu Y, Huang P, Yang N, Liu R, Liu X, Dai H, Zhang L, Song F, Sun C (2017): Establishment and Application of a High Throughput Screening System Targeting the Interaction between HCV Internal Ribosome Entry Site and Human Eukaryotic Translation Initiation Factor 3. Front. Microbiol. 8, 977. https://doi.org/10.3389/fmicb.2017.00977 


\title{
Supplementary information
}

\section{The effects of nucleotide usage in key nucleotide positions +4 and -3 flanking start codon on translation levels mediated by IRES of hepatitis $\mathrm{C}$ virus}

\author{
P. MA ${ }^{1 *}$, X.-X. MA ${ }^{1 *}$, Q.-Y. CHANG ${ }^{1}$, L.-J. LI' ${ }^{1}$, Y.-N. WANG ${ }^{2}$, Y.-P. FENG ${ }^{1}$, Z.-R. MA ${ }^{1 *}$, J.-H. ZHOU ${ }^{2 *}$
}

${ }^{1}$ Center for Biomedical Research, Northwest Minzu University, Lanzhou, 730030, P. R. China;

${ }^{2}$ State Key Laboratory of Veterinary Etiological Biology, Lanzhou Veterinary Research Institute, Chinese Academy of Agricultural Sciences, Lanzhou, 730046, Gansu, P. R. China

Received December 12, 2017; accepted March 20, 2018; October 15, 2018

Table S1. Sequence data of HCV

\begin{tabular}{|c|c|c|c|c|c|}
\hline Acc. No. & Subgenotypes & Acc. No. & Subgenotypes & Acc. No. & Subgenotypes \\
\hline NC_004102 & $1 \mathrm{a}$ & EU781795 & $1 \mathrm{a}$ & EU155329 & $1 \mathrm{~b}$ \\
\hline AF011753 & 1a & EU781794 & 1a & EU155328 & $1 \mathrm{~b}$ \\
\hline AF011752 & $1 \mathrm{a}$ & EU781789 & 1a & EU155327 & $1 \mathrm{~b}$ \\
\hline AF011751 & $1 \mathrm{a}$ & EU781787 & 1a & EU155326 & $1 b$ \\
\hline EU862839 & $1 \mathrm{a}$ & EU781786 & $1 \mathrm{a}$ & EU155324 & $1 \mathrm{~b}$ \\
\hline EU255989 & $1 \mathrm{a}$ & EU781790 & $1 \mathrm{a}$ & EU482888 & $1 b$ \\
\hline EU255984 & $1 \mathrm{a}$ & EU781783 & 1a & EU155330 & $1 \mathrm{~b}$ \\
\hline EU255983 & $1 \mathrm{a}$ & EU781780 & 1a & EU155332 & $1 \mathrm{~b}$ \\
\hline EU255982 & $1 \mathrm{a}$ & EU781777 & $1 \mathrm{a}$ & EU256085 & $1 \mathrm{~b}$ \\
\hline EU255981 & $1 \mathrm{a}$ & EU781774 & $1 \mathrm{a}$ & EU256084 & $1 \mathrm{~b}$ \\
\hline EU255980 & $1 \mathrm{a}$ & EU781768 & $1 \mathrm{a}$ & EU256045 & $1 \mathrm{~b}$ \\
\hline EU255965 & $1 \mathrm{a}$ & EU781760 & $1 \mathrm{a}$ & EU256000 & $1 b$ \\
\hline EU255963 & $1 \mathrm{a}$ & EU256072 & $1 \mathrm{a}$ & EU256066 & $1 \mathrm{~b}$ \\
\hline EU155341 & $1 \mathrm{a}$ & EU256051 & 1a & EU155382 & $1 b$ \\
\hline EU255975 & $1 \mathrm{a}$ & EU256041 & $1 \mathrm{a}$ & EU155357 & $1 \mathrm{~b}$ \\
\hline EU255988 & $1 \mathrm{a}$ & EU256033 & $1 \mathrm{a}$ & EU155356 & $1 b$ \\
\hline EU155343 & $1 \mathrm{a}$ & EU256057 & $1 \mathrm{a}$ & EU155300 & $1 \mathrm{~b}$ \\
\hline EU155338 & $1 \mathrm{a}$ & EU256049 & 1a & EU482881 & $1 \mathrm{~b}$ \\
\hline EU255967 & $1 \mathrm{a}$ & EU256048 & 1a & EU256083 & $1 \mathrm{~b}$ \\
\hline EU255966 & $1 \mathrm{a}$ & EU255934 & 1a & EU256082 & $1 \mathrm{~b}$ \\
\hline EU781802 & $1 \mathrm{a}$ & FJ205868 & $1 \mathrm{a}$ & EU256079 & $1 \mathrm{~b}$ \\
\hline EU781797 & $1 \mathrm{a}$ & FJ205867 & 1a & EU256078 & $1 \mathrm{~b}$ \\
\hline EU781781 & $1 \mathrm{a}$ & EU155238 & 1a & EU256077 & $1 \mathrm{~b}$ \\
\hline EU781779 & $1 \mathrm{a}$ & EU155333 & $1 \mathrm{~b}$ & EU256059 & $1 \mathrm{~b}$ \\
\hline EU781776 & $1 \mathrm{a}$ & EU482849 & $1 \mathrm{~b}$ & EU155374 & $1 b$ \\
\hline EU781799 & 1a & EU155337 & $1 \mathrm{~b}$ & FJ390398 & $1 \mathrm{~b}$ \\
\hline EU781798 & $1 \mathrm{a}$ & EU155334 & $1 \mathrm{~b}$ & FJ390397 & $1 \mathrm{~b}$ \\
\hline EU781796 & $1 \mathrm{a}$ & EU155331 & $1 \mathrm{~b}$ & АВ249644 & $1 \mathrm{~b}$ \\
\hline EU781804 & $1 \mathrm{a}$ & EU155336 & $1 \mathrm{~b}$ & AM910652 & $1 \mathrm{~g}$ \\
\hline EU781800 & $1 \mathrm{a}$ & EU155335 & $1 \mathrm{~b}$ & AB047644 & $2 \mathrm{a}$ \\
\hline
\end{tabular}




\begin{tabular}{|c|c|c|c|c|c|}
\hline Acc. No. & Subgenotypes & Acc. No. & Subgenotypes & Acc. No. & Subgenotypes \\
\hline AB047643 & $2 a$ & EU687194 & $1 \mathrm{a}$ & AY232740 & $2 b$ \\
\hline AB047642 & $2 \mathrm{a}$ & AB520610 & la & AY232739 & $2 b$ \\
\hline AB047641 & $2 \mathrm{a}$ & EU255945 & la & AY232738 & $2 b$ \\
\hline AB047640 & $2 \mathrm{a}$ & EU155346 & la & D50409 & $2 c$ \\
\hline AY232731 & $2 b$ & EU482873 & la & AB031663 & $2 \mathrm{k}$ \\
\hline AY232730 & $2 b$ & D90208 & $1 b$ & D17763 & $3 a$ \\
\hline AB559564 & $2 b$ & D11355 & $1 b$ & D28917 & $3 a$ \\
\hline HM777359 & $2 j$ & D10934 & $1 b$ & AF046866 & $3 a$ \\
\hline FN666428 & $2 q$ & EF638081 & $1 b$ & X76918 & $3 a$ \\
\hline GQ275355 & $3 a$ & AY460204 & $1 b$ & D49374 & $3 b$ \\
\hline FJ407092 & $3 \mathrm{i}$ & AF165064 & $1 b$ & D63821 & $3 \mathrm{k}$ \\
\hline FJ025854 & $4 \mathrm{~b}$ & HCU89019 & $1 b$ & Y11604 & $4 \mathrm{a}$ \\
\hline EU392172 & $4 \mathrm{~d}$ & AF483269 & $1 b$ & DQ418789 & $4 \mathrm{a}$ \\
\hline EU392169 & $4 \mathrm{f}$ & EU857431 & $1 b$ & DQ418788 & $4 a$ \\
\hline EU392173 & $4 \mathrm{k}$ & L02836 & $1 b$ & DQ418787 & $4 \mathrm{a}$ \\
\hline EU392171 & $4 \mathrm{k}$ & GU451224 & $1 b$ & DQ418784 & $4 \mathrm{a}$ \\
\hline NC_009826 & $5 a$ & GU451222 & $1 b$ & DQ418783 & $4 \mathrm{a}$ \\
\hline DQ278892 & 6 & GU451221 & $1 b$ & DQ418782 & $4 \mathrm{a}$ \\
\hline DQ278894 & $6 n$ & GU451220 & $1 b$ & DQ516084 & $4 a$ \\
\hline EF424625 & $6 \mathrm{q}$ & GU451219 & $1 b$ & Y13184 & $5 a$ \\
\hline EU408328 & $6 r$ & GU451218 & $1 b$ & AF064490 & $5 a$ \\
\hline EU408329 & $6 s$ & AF176573 & $1 b$ & AY859526 & $6 a$ \\
\hline EF632071 & $6 \mathrm{t}$ & U01214 & $1 b$ & Y12083 & $6 a$ \\
\hline EU246940 & $6 \mathrm{u}$ & AF333324 & $1 b$ & DQ480518 & $6 a$ \\
\hline EU643834 & $6 w$ & AB426117 & $1 b$ & DQ480517 & $6 a$ \\
\hline M62321 & $1 \mathrm{a}$ & D63857 & $1 b$ & DQ480516 & $6 a$ \\
\hline M67463 & 1a & EF032894 & $1 b$ & DQ480513 & $6 a$ \\
\hline AF009606 & 1a & EF032893 & $1 b$ & DQ480512 & $6 a$ \\
\hline EF032886 & 1a & EF032892 & $1 b$ & DQ480524 & $6 a$ \\
\hline EF407457 & 1a & AY051292 & $1 \mathrm{c}$ & DQ480523 & $6 a$ \\
\hline EF407456 & la & D14853 & $1 \mathrm{c}$ & DQ480520 & $6 a$ \\
\hline EF407455 & $1 \mathrm{a}$ & AY651061 & $1 \mathrm{c}$ & D84262 & $6 b$ \\
\hline EF407454 & 1a & D00944 & $2 \mathrm{a}$ & D84263 & $6 \mathrm{~d}$ \\
\hline EF407453 & 1a & AB047639 & $2 \mathrm{a}$ & DQ835764 & $6 f$ \\
\hline EF407452 & 1a & NC009823 & $2 \mathrm{a}$ & DQ835760 & $6 f$ \\
\hline EF407451 & 1a & AY746460 & $2 \mathrm{a}$ & D63822 & $6 \mathrm{~g}$ \\
\hline EF407450 & 1a & AF238485 & $2 \mathrm{a}$ & DQ314806 & $6 \mathrm{~g}$ \\
\hline EF407449 & 1a & AF238484 & $2 \mathrm{a}$ & D84265 & $6 \mathrm{~h}$ \\
\hline EU155295 & 1a & AF238483 & $2 \mathrm{a}$ & D84264 & $6 \mathrm{k}$ \\
\hline EU155293 & 1a & AF238482 & $2 \mathrm{a}$ & DQ278893 & $6 \mathrm{k}$ \\
\hline EU155292 & la & AF238481 & $2 \mathrm{a}$ & DQ278891 & $6 \mathrm{k}$ \\
\hline EU155291 & 1a & AF169005 & $2 a$ & EU408332 & $6 \mathrm{u}$ \\
\hline EU155290 & 1a & D10988 & $2 b$ & EU408331 & $6 \mathrm{u}$ \\
\hline EU155289 & 1a & AB030907 & $2 b$ & EU408330 & $6 \mathrm{u}$ \\
\hline EU155288 & 1a & AY232745 & $2 \mathrm{~b}$ & EU798760 & $6 \mathrm{v}$ \\
\hline EF032883 & 1a & AY232744 & $2 b$ & FJ435090 & $6 \mathrm{v}$ \\
\hline EU256074 & 1a & AY232743 & $2 b$ & EU798761 & $6 \mathrm{v}$ \\
\hline EU155347 & $1 \mathrm{a}$ & AY232742 & $2 b$ & EU158186 & $6 \mathrm{v}$ \\
\hline EU256106 & $1 \mathrm{a}$ & AY232741 & $2 b$ & EF108306 & $7 \mathrm{a}$ \\
\hline
\end{tabular}


Table S2. Oligonucleotides for PCR obtaining CAT, EGFP and IRES sequences

\begin{tabular}{cl}
\hline Primer & Sequence $\left(\mathbf{5}^{\prime} \rightarrow \mathbf{3}^{\prime}\right)$ \\
\hline F-CAT & ATGGAGAAAAAAATCACTGGATATA \\
R-CAT & TTACGCCCCGCCCTGCCACTCATCG \\
F-EGFP & ATGGAAGTGAGCAAGGGCGAGGAGCTGTTCAC \\
R-EGFP & TTACTTGTACAGCTCGTCCATGCCGAGAG \\
F-IRES & ATGAGTGGCAGGGCGGGGCGTAACCTGTGAGGAACTACTGTCTTCA \\
R-IRES & AGCTCCTCGCCCTTGCTCACCATGGTGCACGGTCTACGAGACCTCC \\
\hline
\end{tabular}

Table S3. Oligonucleotides used for fusion PCR obtaining the fragment of CAT-IRES

\begin{tabular}{ll}
\hline Primer & Sequence $\left(5^{\prime} \rightarrow 3^{\prime}\right)$ \\
\hline F-CAT & 5'-CGGGATCCATGGAGAAAAAAATCACTGG-3' $^{\prime}$ \\
R-CAT & 5'-TTACGCCCCGCCCTGCCACTC-3' \\
F-IRES & 5'-TGGCAGGGCGGGGCGTAACCTGTGAGGAACTACTGTCTTC-3' $^{\prime}$ \\
R-IRES & 5'-GCACGGTCTACGAGACCTCC-3' $^{\prime}$ \\
\hline
\end{tabular}

Note: The primer F-CAT contains BamHI site. The primer F-IRES contains the 3'end of CAT coding sequence and the 5'end of IRES sequence.

Table S4. Oligonucleotides used for fusion PCR obtaining the fragment of CAT-IRES-EGFP

\begin{tabular}{cl}
\hline Primer & Sequence (5' $\rightarrow$ 3' $\left.^{\prime}\right)$ \\
\hline F-CAT & 5'-CGGGATCCATGGAGAAAAAAATCACTGG-3' \\
F-EGFP* & 5'-AGGTCTCGTAGACCGTGCTCCatggtgagcaagggcgaggagctgttcac-3' \\
F-EGFP* & 5'-AGGTCTCGTAGACCGTGCTCCatgctgagcaagggcgaggagctgttcac-3' \\
F-EGFP* & 5'-AGGTCTCGTAGACCGTGCTCCatgttgagcaagggcgaggagctgttcac-3' \\
F-EGFP* & 5'-AGGTCTCGTAGACCGTGCTCCatgatgagcaagggcgaggagctgttcac-3' \\
F-EGFP* & 5'-AGGTCTCGTAGACCGTGCCCCatggtgagcaagggcgaggagctgttcac-3' \\
F-EGFP* & 5'-AGGTCTCGTAGACCGTGCCCCatgctgagcaagggcgaggagctgttcac-3' \\
F-EGFP* $^{*}$ & 5'-AGGTCTCGTAGACCGTGCCCCatgttgagcaagggcgaggagctgttcac-3' \\
F-EGFP* & 5'-AGGTCTCGTAGACCGTGCCCCatgatgagcaagggcgaggagctgttcac-3' \\
F-EGFP* & 5'-AGGTCTCGTAGACCGTGCACCatggtgagcaagggcgaggagctgttcac-3' \\
F-EGFP* & 5'-AGGTCTCGTAGACCGTGCACCatgctgagcaagggcgaggagctgttcac-3' \\
F-EGFP* & 5'-AGGTCTCGTAGACCGTGCACCatgttgagcaagggcgaggagctgttcac-3' \\
F-EGFP* & 5'-AGGTCTCGTAGACCGTGCACCatgatgagcaagggcgaggagctgttcac-3' \\
F-EGFP* & 5'-AGGTCTCGTAGACCGTGCGCCatggtgagcaagggcgaggagctgttcac-3' \\
F-EGFP* & 5'-AGGTCTCGTAGACCGTGCGCCatgctgagcaagggcgaggagctgttcac-3' \\
F-EGFP* & 5'-AGGTCTCGTAGACCGTGCGCCatgttgagcaagggcgaggagctgttcac-3' \\
F-EGFP* & 5'-AGGTCTCGTAGACCGTGCGCCatgatgagcaagggcgaggagctgttcac-3' \\
R-EGFP & 5'-GCTCTAGATTACTTGTACAGCTCGTCCA-3' \\
\hline
\end{tabular}

Note: The primer F-CAT contains BamHI site. The 16 primers F-EGFP ${ }^{\star}$ are composed of the 3 ' end of IRES element and EGFP coding sequence. Each F-EGFP primer contains the specific nucleotide usage at the positions -3 and +4 . The positions -3 and +4 have been marked in yellow color. 


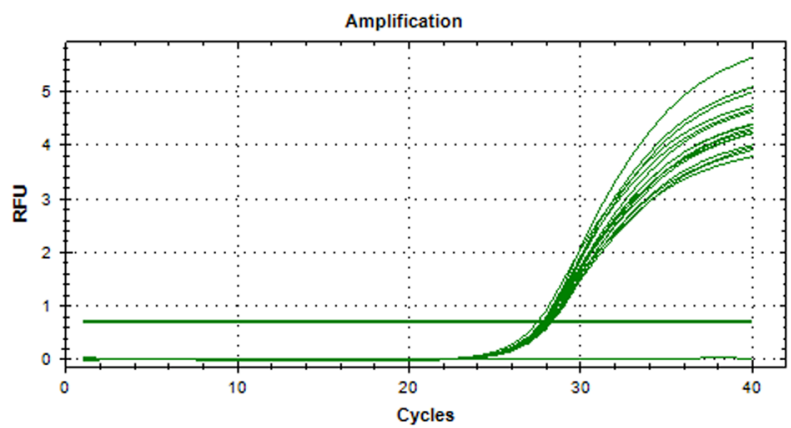

Fig. S1

Amplification plot for reporter RNAs 